\title{
Comparing student performance in thermodynamics using the flipped class- room and think-pair-share pedagogies
}

\section{James V Canino, Trine University}

Jamie Canino is currently an associate professor at Trine University where he focuses on undergraduate education research. He teaches in the thermal-fluids and aerospace engineering fields and can be reached at caninoj@trine.edu. 


\title{
Comparing Student Performance in Thermodynamics using the Flipped Classroom and Think-Pair-Share Pedagogies
}

\begin{abstract}
Recently, significant numbers of instructors in higher education have employed the flipped classroom, or inverted classroom, pedagogy. Studies have found varying degrees of success of the flipped classroom in increasing student achievement. However, previous results from the author indicate that a significant time investment by the instructor is required to produce the required content for a flipped classroom. The Think-Pair-Share pedagogy is one of many active learning methods that have been shown to be successful in increasing student performance over non-active lectures. Furthermore, most teachers agree that incorporating Think-Pair-Share questions into their lectures does not require too much time reworking their notes. The goal of this research was to determine if student performance in thermodynamics on both computational and conceptual questions was increased when the flipped classroom model was used compared to students who were instructed using the Think-Pair-Share model. For this study in the Fall of 2013, two sections of thermodynamics at Trine University were taught by the same instructor using the same homework and exams. For the first section $(\mathrm{N}=20)$ the students were instructed using the flipped classroom model. For the second section $(\mathrm{N}=8)$ the students were instructed using the Think-Pair-Share model. While the relatively small number of students limits the statistical significance of this study, results indicate that there was no difference between the educational performance of these two groups on either computational or conceptual tasks as indicated by their exam scores. However, students in the flipped classroom did state that they enjoyed the flipped classroom model and wished that more faculty members used this method.
\end{abstract}

\section{Introduction}

The flipped classroom, or inverted classroom, pedagogy has been one of the most widely researched pedagogies in the last few years. A search in the ASEE paper database reveals hundreds of papers on the flipped classroom. Bishop and Verleger ${ }^{1}$ provide a summary of some of the important results from the literature up to 2012. While many studies indicate that the flipped classroom model yields better students outcomes ${ }^{2-6}$ other studies have noted that there is no improvement in student performance when the flipped model is used ${ }^{7-11}$. Although some of the studies that show a flipped classroom does not work suggest that the faculty member's implementation of the flipped classroom may be at fault and not the flipped pedagogy itself. Moreover, Redekopp and Ragusa provide evidence that the flipped classroom pedagogy does not improve lower-order learning outcomes, but it does improve higher-order learning outcomes. ${ }^{12}$ The objective of this study is to determine if the flipped classroom pedagogy will improve student learning in thermodynamics at a small Midwestern university.

While there is some conflicting evidence regarding the efficacy of the flipped classroom it seems reasonable to place the flipped classroom pedagogy within the context of other active learning methods. Since it is well documented that active learning environments are better for student learning than traditional lectures, it was decided that student outcomes using the flipped classroom pedagogy would be compared to student outcomes from the Think-Pair-Share pedagogy ${ }^{13,14}$. Think-Pair-Share ${ }^{15-17}$ utilizes short questions interspersed throughout a lecture to 
engage the students in the material being presented. First, the instructor asks a question, usually in multiple-choice form, and all of the students answer the question on their own. Second, students discuss their answers to the question with a peer. Finally, after the discussion, all of the students answer the question again. Often the students in the classroom converge on the correct response after discussing the question with their peers. ${ }^{18}$ The Think-Pair-Share pedagogy was selected for comparison since implementing it in a class is fairly easy and did not require a significant redesign of the instructor's notes. Additionally, implementing the Think-Pair-Share method in thermodynamics was made even easier by the development of the AIChE Concept

Warehouse, ${ }^{19}$ which has hundreds of concept questions that instructors can use for free.

The driving motivation for this study is the comment from Bishop and Verleger that states, "We suggest that in order to ensure progress, future research on the flipped classroom should employ controlled studies that objectively examine student performance throughout a semester, with both traditional and concept-inventors style problems." ${ }^{1}$ Therefore, this research study was constructed to satisfy this statement to the best of the author's ability.

\section{Study Design}

Two sections of thermodynamics were taught by the author during the same semester. Students in one section were taught using the flipped classroom pedagogy, while students in the second section were instructed using the Think-Pair-Share methodology. There were 20 students in the flipped section with class periods on Tuesdays and Thursdays from 11:00 am to 12:15 pm. Students in the flipped classroom watched several videos and answered several concept questions (usually four) before coming to class. Each video was between 3 and 35 minutes long. The length of the videos was selected such that an entire concept or example could be explained within a single video. Moreover, students were awarded points for answering the concept questions regardless of whether the answer was correct. During class time the students were free to work in groups on the homework problems and request assistance from the professor. Usually students only finished a fraction of the homework problems in class and were required to complete the rest of the assignment outside of class. Graded homework was collected daily.

The Think-Pair-Share section of thermodynamics had eight students and the class periods were on Mondays, Wednesdays, and Fridays from 12:00 to 12:50 pm. During the class, the author lectured in his normal style which includes fill-in-the-blank notes, however, approximately three concept questions, that the students answered using clickers, were added. The concept questions used during the Think-Pair-Share class were the same concept questions that the flipped classroom students were assigned to answer after watching the videos at home. Also, the lecture used the exact same instructor and student notes that were presented in the videos to the students in the flipped classroom section. Again, students were given points for participating in the ThinkPair-Share activity regardless of their answer. Moreover, the students in the Think-Pair-Share section were assigned the same homework problems as the students in the flipped classroom.

Exams were given during the evenings so that students from both sections of the class could take the exact same exam. Students had 90 minutes to complete the exam and no student commented in the course review that the exams could not be completed during the time given. A typical exam would consist of three tradition problems along with five concept-inventory style 
problems. The two hour final exam was composed of five traditional problems and eight concept-inventory style problems. Four of the eight concept-inventory problems on the final had been on previous exams. The scores on the exams were the primary mechanism for evaluating the efficacy of the flipped classroom pedagogy over the Think-Pair-Share pedagogy.

Moreover, neither the author nor the students knew which pedagogy would be used before registering for the Fall 2013 classes. The author had previous experience with the flipped classroom and believes that it is important to have students in a classroom where they can gather in small groups around tables and collaborate. ${ }^{20}$ Trine University has a Project-Based Learning (PBL) classroom that has movable tables so that students can more easily collaborate. This classroom is generally used by the School of Education, but can be used by other faculty subject to School of Education's approval. It was determined shortly before the start of classes that the PBL classroom would only be available for the author's use during the Tuesday/Thursday time slot. Therefore, this was the section that was assigned to the flipped classroom pedagogy. So it would appear that the thermodynamics section which was flipped had a larger number of students than the Think-Pair-Share section due to the way the class fit into the students' overall schedule.

Additionally, the schedule (TTh versus MWF) and the number of people in the classes (20 versus 8) are clear difference between the flipped classroom group and the Think-Pair-Share group. It is the author's opinion, though, that the number of students had no overall effect on student achievement in this case. This is based on anecdotal evidence from the author's own history having taught thermodynamics six times prior to this study. These six classes varied in size between 8 and 29 students and there seemed to be very little difference in the students' overall performance in these classes. The author has no experience concerning the effect of class schedule since the Fall of 2013 was the first time the author taught thermodynamics on a Tuesday/Thursday schedule. A cursory search of the ASEE conference proceedings found no information on this topic. Since almost every university in the country has classes on T/TH and MWF schedules it seems reasonable to assume that the professoriate as a whole does not perceive major differences between these two schedules, otherwise one of these schedules surely would have been eliminated.

Finally, it is conceivable that the students in the Think-Pair-Share classroom also watched the videos that were posted for the flipped classroom, even though it would have required the students in the Think-Pair-Share classroom to obtain the videos from a student in the flipped classroom section. However, it seems unlikely that the students in the Think-Pair-Share class did this before lecture since it did not appear to the author that the students were more prepared for the lecture than previous classes. It might be more likely that the Think-Pair-Share students watched the videos before the exam. However, after inspecting the advanced statistics on the Vimeo website it appears that the lectures were only watched just before class time for the flipped classroom. So while it cannot be stated definitively that the Think-Pair-Share students did not watch the videos is seems somewhat unlikely. 


\section{Student Performance in the Flipped Classroom}

All 28 students were men between the ages of 19 and 26, who are enrolled at Trine University full-time. Twenty-seven of the students would be labeled as traditional students. One student, the 26 year-old, was a veteran who was returning to school. However, even this student was a full time student who attended classes during the day and might be considered a traditional student by some. Additionally, 27 of the 28 students were US citizens with almost all of the US students hailing from Indiana, Illinois, and Ohio. Finally, 26 of the 28 students are Caucasian.

First, the author was interested to see if students would stop watching the videos before class as the semester progressed. As shown in Figure 1, the total number of unique views of the lecture videos was recorded for several class periods during the first half of the semester.

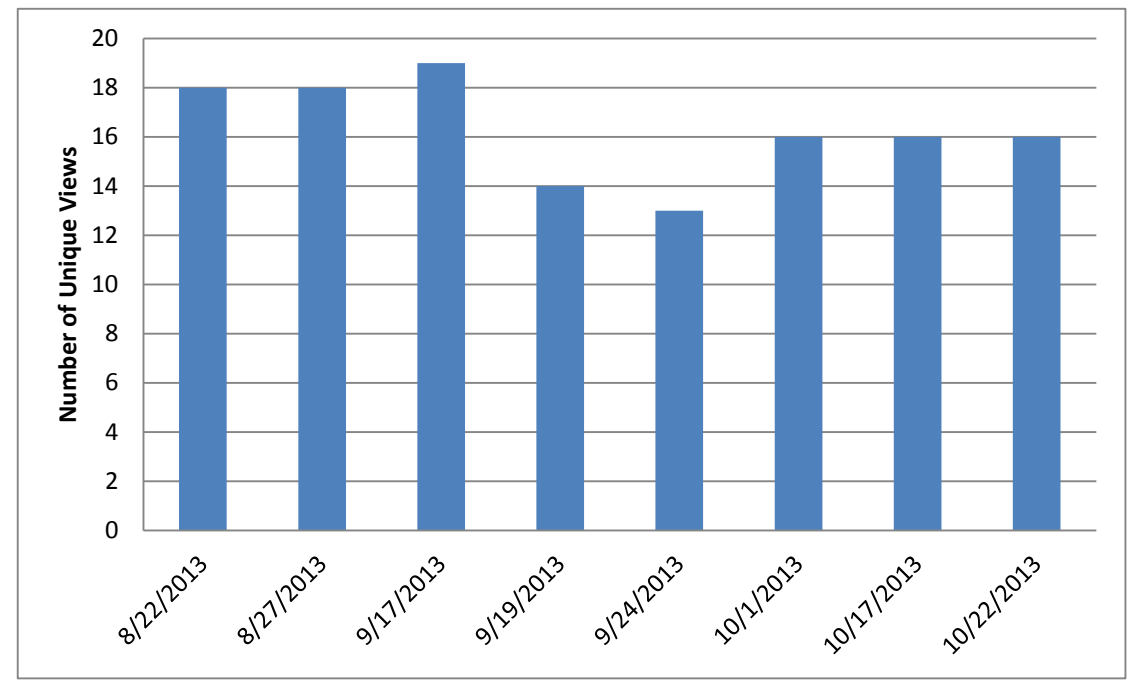

Figure 1. Number of unique views of the flipped classroom lectures for a selection of class periods

August $22^{\text {nd }}$ was the first class period that students were expected to watch videos. It is interesting to note that only 18 of the 20 students appeared to watch the videos associated with that lecture. However, upon further investigation it was learned that the other two students watched the lecture with a classmate. Since students did watch the videos in groups the absolute number of unique views may not be meaningful. However, the relative number of unique views is probably meaningful. There was a noticeable dip in the views in mid-September, but the number of unique views rebounded in October. Unfortunately, data regarding unique views were not collected after October $22^{\text {nd }}$.

The average scores on the three semester exams as well as the Final Exam are shown in Figure 2 for both the Think-Pair-Share section and the flipped classroom section. The bars indicate one standard deviation in the students' exam grades. 


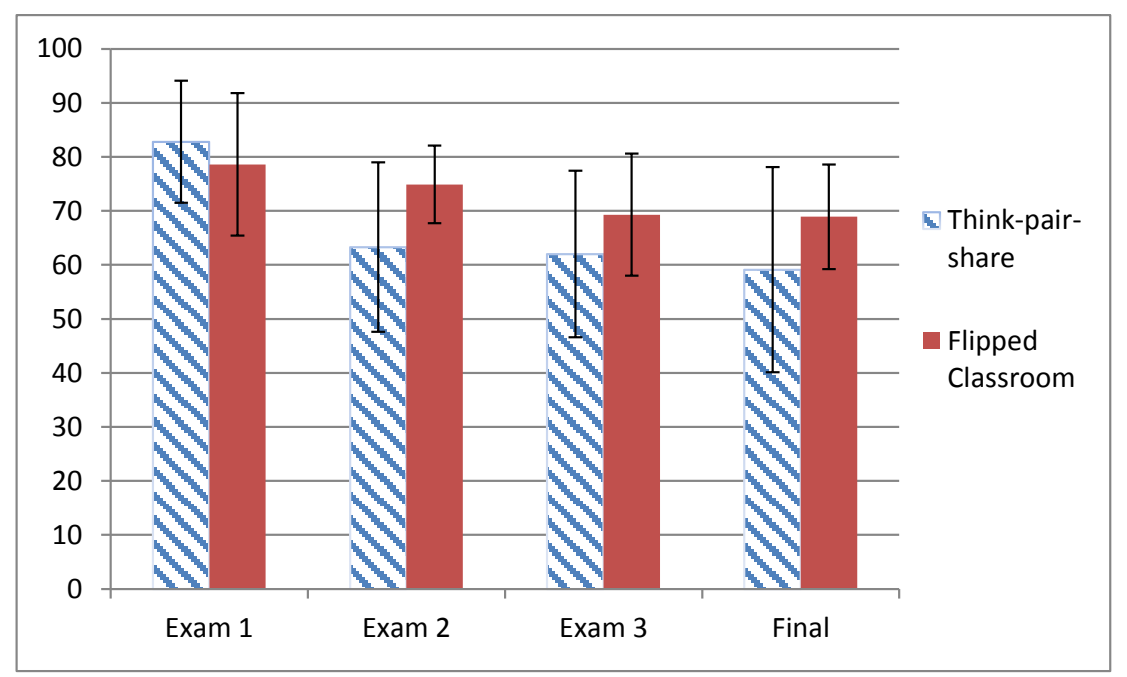

Figure 2. Average exam grades. Bars indicate one standard deviation

Additionally, the average number of concept questions that were answered correctly in each section is shown in Figure 3. Again, the bars indicate one standard deviation in the students' grade. Recall that five concept-inventory style questions were asked on Exams 1, 2 and 3, but eight concept-inventory type questions were asked on the Final Exam.

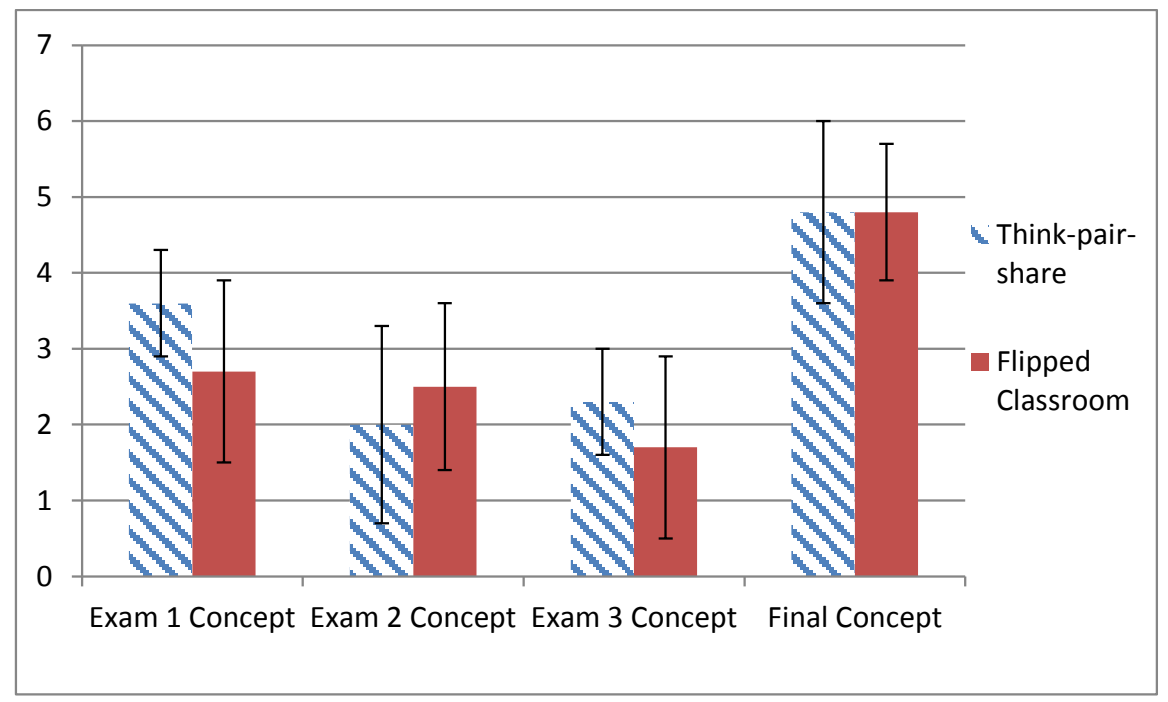

Figure 3. Average number of concept-inventory style questions answered correctly. Bars indicate one standard deviation

Eight, two-tailed t-tests were conducted to determine if the mean score from the flipped classroom was larger than the mean score of the Think-Pair-Share classroom on any of the overall exam scores or the concept-inventory style problems for all four exams. The only result to be found significant $(\mathrm{p}<0.05)$ was the average Exam 2 score for the flipped classroom $(74.9 \%)$ was higher than the Think-Pair-Share mean (63.25\%). It should be noted for this case that the pvalue was 0.049 indicating the computed t-value was barely below the critical t-value. Since only one of eight hypothesis tested were found to be significant, this study finds little to no evidence that students instructed using the flipped classroom model perform better than students instructed 
using the Think-Pair-Share model on either traditional or concept-inventory style problems on exams.

\section{Students' Perceptions of Flipped Classroom}

An anonymous survey with 21 multiple-choice questions and one free response section was completed by 19 of the 20 students in the flipped classroom. This section will report some of the results from that survey.

First, 18 of the 19 students reported stopping and replaying parts of the lecture videos. Of those 18 students, 13 of them indicated that they stopped the video because they did not understand the concept and wanted to rehear the explanation. This is one of the commonly cited reasons in favor of the flipped classroom model. Secondly, ten students strongly agreed and eight students agreed with the statement that they "wished more engineering classes used the flipped classroom model." The fact that students liked the flipped classroom model was reinforced by the statements in the free response section. Some of these statements, taken verbatim from the survey, were:

"Flipped class was very helpful. Very useful when it came to reviewing for exams and working on homework. You should definitely do thermo 2 like this."

"The flipped classroom was helpful since I was able to complete notes in my room while coming to ask questions when I needed."

"Having the professor available when doing homework was strongly helpful. It allowed me to ask any little questions or get something clarified. This helped me better understand concepts when working problems on my own."

Perhaps the most interesting response in the survey was that two students strongly agreed and ten students agreed with the statement "I believe I am a more independent learner than I was previously to the flipped thermodynamics class." This study was not constructed to determine if students in the flipped classroom truly became more independent learners. However, if the students' perception is true, then using the flipped classroom model might assist in meeting the ABET requirement that students have the "ability to engage in life-long learning". ${ }^{21}$

Finally, 10 students strongly agreed and seven students agreed with the statement "I believe I learned more in thermodynamics because of the flipped classroom." The students' belief that they learned more is echoed in several student comments as shown below.

"I loved the flipped classroom. I felt like I had a much broader understanding of thermodynamics due to the flipped classroom format. If I needed to pause a lecture to let my writing catch up, I could, which was very useful."

"I would like my Thermo II class to be a flipped class because I felt that having the flipped class made it easier to get the main points out of each video." 
Perhaps the most stunning comment of all was the following:

"PLEASE FLIP EVERY CLASS it works really well. Thermo did not seem as difficult as the rumors led me to believe. I think this is because of the flipped class."

Despite the evidence shown in this paper that the flipped classroom does not improve student learning, the students believed it helped their learning. Furthermore, some students even attributed their success in the class to the flipped classroom model.

Students in the Think-Pair-Share classroom were also asked to fill out an online survey. Unfortunately, only one of the eight students filled out the survey. The problem-based learning classroom had computers in the classroom so the author asked each student in the flipped classroom to fill out the survey during class time. However, no computers were available in the Think-Pair-Share classroom. The author asked the students in the Think-Pair-Share classroom several times to complete the survey and even ended class early one day so that students could take the survey. Unfortunately, only the one student took the survey so, in general, the thoughts of the students in the Think-Pair-Share classroom remain unknown.

\section{Changes to Future Implementations}

The author is considering adding so-called "entrance quizzes" when the flipped classroom pedagogy is used in the future. This change is due to discussions with Dr. Brett Batson, a colleague at Trine University, and based on advice received during an ASEE workshop ${ }^{22}$. Although it is not entirely clear to the author if daily quizzes or the flipped teaching style is leading to the perceived improvement in students' learning. However, the answer to that question will probably remain unknown since it is the removal of course content from class time by flipping that has allowed the addition of daily quizzes.

\section{Conclusion}

This study finds that male students at a small Midwestern university seemed to enjoy the flipped classroom model and the students believed that the flipped classroom helped them learn more. However, students' performance on the exams was not improved over students instructed using the Think-Pair-Share pedagogy. It is important to note that this study also found no evidence that students taught using the Think-Pair-Share model perform better on exams than students who were taught using the flipped classroom. Therefore, one might hypothesize that the students' academic achievement in a flipped classroom would be better than their performance in a nonactive learning classroom. However, this study had a very small sample size and, therefore, lacks strong statistical power. The author would like to collect additional data on this topic but he has not taught thermodynamics since this study was conducted in the Fall of 2013.

Additionally, since class time is available for other activities it is possible that providing class time activities other than simply working homework problems might lead to more learning. Consequently, a study focusing on the most effective way to use classroom time (e.g., homework problems, quizzes, labs, field trips, etc.) when content coverage is not an issue would be useful for instructors who are currently using the flipped classroom model. Finally, a study focused on objectively assessing if the flipped classroom improves students' ability to learn independently 
could help determine if the flipped classroom has advantages outside of students' immediate content learning.

\section{References}

1. Bishop, Jacob L. and Matthew A. Verleger, "The Flipped Classroom: A survey of the Research". Proceedings of the $120^{\text {th }}$ ASEE Annualk Conference \& Exposition. Atlanta, Georgia, 23-26 June 2013. ASEE, 2013. Internet. 19 January 2015.

2. Bergmann, Jonathan, and Aaron Sams. Flip Your Classroom Reach Every Student in Every Class Every Day. Eugene, Or.: International Society for Technology in Education, 2012.

3. Mason, G.S.; Shuman, T.R.; Cook, K.E., "Comparing the Effectiveness of an Inverted Classroom to a Traditional Classroom in an Upper-Division Engineering Course," Education, IEEE Transactions on, vol.56, no.4, pp.430-435, Nov. 2013.

4. Bachnak, Rafic A. and Sofia Carolina Maldonado, "The Flipped Classroom Experience: Approach and Lessons Learned". Proceedings of the $121^{\text {st }}$ ASEE Annual Conference \& Exposition. Indianapolis, IN, 15-18 June 2014. ASEE, 2014. Internet. 2 January 2015.

5. Mason, G., T. R. Shuman, et al."Inverting (Flipping) Classrooms - Advantages and Challenges". Proceedings of the 120 th ASEE Annual Conference \& Exposition, Atlanta, GA, 23-26 June 2013. ASEE, 2013.

6. Conner, Kenneth A., Newman, Dianna L., and Meghan Morris Deyoe "Flipping a Classroom: A Continual Process of Refinement". Proceedings of the $121^{\text {st }}$ ASEE Annual Conference \& Exposition. Indianapolis, IN, 15-18 June 2014. ASEE, 2014. Internet. 2 January 2015.

7. Lape, Nancy K., Rachel Levy, Darryl Yong, Karl Haushalter, Rebecca Eddy, and Nancy Hankel, "Probing the Inverted Classroom: A controlled Study of Teaching and Learning Outcomes in Undergraduate Engineering and Mathematics". Proceedings of the $121^{\text {st }}$ ASEE Annual Conference \& Exposition. Indianapolis, IN, 15-18 June 2014. ASEE, 2014. Internet. 2 January 2015.

8. McClelland, Carrie J., "Flipped a Large-enrollment Fluid Mechanics Course - Is it Effective?", Proceedings of the 120 $0^{\text {th }}$ ASEE Annual Conference \& Exposition. Atlanta, Georgia, 23-26 June 2013. ASEE, 2013. Internet. 2 January 2015.

9. Mason, Gregory, Teodora R. Shuman, and Kathleen E. Cook, "Inverting (Flipping) Classrooms - Advantages and Challenges". Proceedings of the $120^{\text {th }}$ ASEE Annual Conference \& Exposition. Atlanta, Georgia, 23-26 June 2013. ASEE, 2013. Internet. 19 January 2015.

10. Cavalli, Matthew K., Neubert, Jeremiah J., McNally, Dustin, and Debbie Jacklitch-Kuiken, "Comparison of Student Performance and Perceptions Across Multiple Course Delivery Modes". Proceedings of the $121^{\text {st }}$ ASEE Annual Conference \& Exposition. Indianapolis, IN, 15-18 June 2014. ASEE, 2014. Internet. 2 January 2015.

11. Thomas, J. and T. Philpot, "An Inverted Teaching Model for a Mechanics and Materials Course," Proceedings of the 119 $9^{\text {st }}$ ASEE Annual Conference \& Exposition. San Antonio, TX, 10-13 June 2012.

12. Redekopp, Mark W., and Giesele Ragusa, "Evaluating Flipped Classroom Strategies and Tools for Computer Engineering". Proceedings of the $120^{\text {th }}$ ASEE Annual Conference \& Exposition. Atlanta, Georgia, 23-26 June 2013. ASEE, 2013. Internet. 1 February 2015.

13. Freeman, Scott, Sarah L. Eddy, Miles McDonough, Michelle K. Smith, Nnadozie Okoroafor, Hannah Jordt, and Mary Pat Wenderoth, "Active learning increases student performance in science, engineering, and mathematics" PNAS 2014111 (23) 8410-8415; published ahead of print May 12, 2014, doi:10.1073/pnas.1319030111.

14. Prince, Michael, "Does Active Learning Work? A Review of the Research" J. Eng. Education, 93(3) 223-231, 2004.

15. Lyman, F., "Think-Pair-Share: An Expanding Teaching Technique," MAACIE, Cooperative News, 1, 1, 1987.

16. Kothiyal, Aditi, Majumdar, Rwitajit, Murthy, Sahana, and Sridhar Iyer, "Effect of think-pair-share in a large CS1 class: 83\% sustained engagement". Proceedings of the ninth annual international ACM conference on International computing education research, Auckland, New Zealand, 10-12 September 2012.

17. Lea, Bih-Ru, "Clickers Adoption in a Small Class Setting," Decision Line, July 2008. 
18. Smith, M. K., W. B. Wood, W. K. Adams, C. Wieman, J. K. Knight, N. Guild, and T. T. Su. "Why Peer Discussion Improves Student Performance On In-Class Concept Questions." Science: 122-24.

19. "AIChE Concept Warehouse." AIChE Concept Warehouse. Web. 19 Jan. 2015.

<http://jimi.cbee.oregonstate.edu/concept_warehouse/CW.php>.

20. Canino, J. "Views on Flipping Engineering Thermodynamics," ASEE Illinois/Indiana Section Conference, April 6, 2013, Angola, IN. 〈http://ilin.asee.org/2013/index_files/canino2.pdf>

21. ABET, "Criteria for Accrediting Engineering Programs", 2013-2014.

22. Zappe, Sarah E. and Stephanie B. Velegol, "So you want to flip your course? Suggestions and experiences from the front line", Workshop as part of the 121 ${ }^{\text {st }}$ ASEE Annual Conference \& Exposition, 15 June 2014. 